\title{
A IMPORTÂNCIA DAS PROVAS DE DESPITAGEM DA BACTERIĹRIA ASSINTOMÁTICA EM SERVIÇOS DE PRÉ-NATAL
}

Cyro Ciari Junior *

Pedro Augusto Marcondes de Almeida* Sebastião Timo Iaria **

Arnaldo Augusto Franco de Siqueira *

\begin{abstract}
RSPL-B/244
Ctari Jr., C. et al. - A importancia das protas de despistagem da bacteriuria assintomática em serviços de pré-natal. Rev. Saúde públ., S. Panlo, 9: 25-31, 1975 .

Restmo: Foram realizadas algumas provas de despistagem da bacteriuma assintomática em 103 gestantes agrupadas segundo a época de gestaçäo, comparativamente com resultados de urocultura. Conclum-se pela importancia da prou do nitrito em tubo. para triagem inicial das bacteriarias assintomaticas no elolver da gestação.
\end{abstract}

Unitermos: Assistencia prénatal. Bacteriuria Assintomatica - Provas de despistagem.

\section{NTRODLCAO}

$\hat{E}$ do conhecimento geral que a freqüência das infecções das vias urinárias durante o ciclo gravidico puerperal é elevada. Fatores predisponentes, alguns ainda não totalmente elucidados. sempre estão presentes nesta época, favorecendo o aparecimento de infecções. O tonus e o peristaltismo dos ureteres diminuem desde o início da gestação. Há estase urinária e - refluxo vésico-ureteral aumenta durante a gravidez como afirma Hutch e col." (1963). Sala e Rubi ${ }^{15}$ (1967) provaram. também. que ocorre uma diminuição da pressão contractil média dos ureteres. Todos estes fatores favorecem a obstrução das vias urinárias e facilitam a invasão e a proliferação de hactérias. como também, a exacerhação de hacteriúrias anteriores silenciosas.

Testes últimos anos. a atenção dos médicos, tem-se roltado. particularmente, para as infecçôes silenciosas das vias urinárias. A infecção urinária aguda suscita poucos problemas de diagnóstico, porém o da bacteriúria assintomática implica, todaria. em grande precisão dos critérios de diagnóstico convencionais para uma maior utilização da medida preventiva.

Por bacteriúria assintomática. entende-se uma bacteriúria significativa e persistente. Este aspecto é importante. pois não é ne-

* Da Disciplina Higiene Materna do Depto de Prática de Saúde Pública da Faculdade de Saúde Pública da USP - Av. Dr. Arnaldo, 715 - São Paulo, SP - Brasil

* Do Dept.o de Nicrobiologia e Imunologia do Instituto de Ciencias Biomedicas da USP Av. Dr. Arnaldo, 715 - São Paulo, SP - Brasil 
CIARI Jr. C et al - A importancia das provas de despistagem da bacteriúria assintomática em serviços de pré-natal, Rer. Saúle públ, S Faulo, 9:25-31. 1975.

cessário tratar sistematicamente todos os casos apresentando hacteriúria. O problema foi resolvido graças às uroculturas. tendo sido fixado um limite de 100.000 bactérias $/ \mathrm{ml}$ de urina entre a contaminação e a infecção real (Kass ': 1965). Acima deste valor a hacteriúria é significativa. O conceito de persistência é variável: para alguns. refere-se a duas coletas. para outros, mais: no entanto a maioria opta por tratamento. com apenas uma cultura revelando contagem bacteriana igual ou superior a 100.000 germes $/ \mathrm{ml}$ de urina.

Yas mulheres a frequência das bacteriúrias assintomáticas aumenta com o início da rida sexual. É de cerca de $l^{C} c$ nas crianças do sexo feminino durante a idade escolar (Kunin e col. ". 1964). Nas multíparas casadas é de 1 a $2^{\circ} \mathrm{c}$. sendo inferior à das mulheres grávidas (Kass: 1965). Durante a graridez. varia de acordo com a raça e a população entre 2 a $10 \%$. situando-se habitualmente entre 1 e 7 r r

A importância destas afecções assintomáticas. se revela pelo fato de que no adulto jovem, cujo rim está irremediávelmente lesado por uma pielonefrite crônica. não se descobre. em geral. pela anamnese. infecção urinária sintomática.

Ja gestação, a bacteriúria assintomática. freqüentemente. evolui para uma pielonefrite aguda. Assim. Whaller ${ }^{1 s}$ (1967). observou que existe uma relação efetiva entre a bacteriúria assintomática e a pielonefrite aguda. em $30 \%$ dos casos. Paralelamente, a freqüência é de apenas $1.8^{\circ} c$ nas mulheres grávidas não sofrendo de bacteriúria assintomática. É claro que pode ocorrer pielonefrite aguda sem que. previamente. tenha existido bacteriúria. Entretanto. o diagnóstico e o tratamento precoce das bacteriúrias assintomáticas na gravidez diminui de dois terços. no mínimo, a freqüência da infecção urinária na gestação. Isto é de importância capital para o obstetra. pois. como sabemos a pielonefrite aguda na gestação pode acarretar uma série de intercorrências durante o ciclo gravídico puerperal. assim como. óbito fetal e prematuridade. Neste ultimo aspecto é importante ressaltar que. segundo

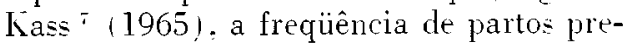
maturos é infinitamente menor num grupo de pacientes com bacteriúria assintomática tratada $\left(7 C_{c}\right)$. do que num grupo de doentes sofrendo da mesma doença. aos quais não foi dado nenhum tratamento $127 \%$. Alguns autores não revelam tal aspecto em seus estudos. como Little ${ }^{11}$ 11965 ) e Henderson e Reinte ${ }^{\star}(1965)$ enquanto que Stuart e col. ${ }^{25}(1965)$ e Layton $^{10}$ (1961) e Rannevick it (1966) confirmam as obserrações de Kass. existindo uma relação entre as hacteriúrias assintomáticas e os partos prematuros.

O diagnóstico da bacteriúria assintomática. para ser feito, necessita de se hasear na existência de uma hacteriúria significativa, admitindo-se que uma contagem de bactérias de $100.000 / \mathrm{ml}$ de urina, marca a fronteira entre a infecção e a contaminação.

A urocultura é um método conveniente. porém. é demorado e caro. Segundo a maioria dos autores. a colheita da urina é essencial e, além do mais. deveremos sempre realizar exames bacteriológicos seriados. o que dificulta a utilização daquele método. em Serviços de Prenatal com número de consultas elevado. na triagem de casos de bacteriúria assintomática. Graças a esta dificuldade. várias provas mais simtples. porém menos exatas. estão sendo empregadas para a despistagem das infecções urinárias.

Estas provas tornam-se positivas quando detectam urinas com bacteriúrias acima de $100.000 / \mathrm{ml}$. A prova de despistagem ideal seria a que permitisse o exame rápido de um grande número de gestantes. por um processo simples e econômico.

Além do mais, as infecções das rias urinárias durante a gestação são. na sua grande maioria, devidas a bastonetes gramnegativos. habitualmente Escherichia coli e Proteus sp. e ainda. mais raramente. a cocos-gram-positivos.

Baseados em todos estes aspectos. resolvemos estudar. comparatiramente. a urocultura e algumas provas simples de des- 
CIARI Jr, C et al - A importâncıa das provas de despistagem da bacteriúria assintomática em serviços de pré-natal. Rer. Saúde puibl., S. Paulo, 9:25-31. 1975.

pistagem de bacteriúria assintomática aplicáveis em Saúde Pública.

As gestantes assim triadas. seriam então submetidas a exames mais complexos, com o fim de se confirmar o diagnóstico e estabelecer o tratamento.

\section{MATERIAL E MÉTODOS}

Ltilizamo-nos de 103 gestantes matriculadas no Serviço de Pré-Natal do Centro de Saúde "Geraldo de Paula Souza" de São Paulo. Estas gestantes eram selecionadas, desde que não apresentassem queixa. do ponto de vista de infecção urinária e. também, nenhum sinal de infecção ao exame clínico e obstétrico. A distribuição das gestantes, segundo a época de gestação, pode ser observada na Tabela 1 .

T A BELA 1

Distribuição das gestantes, segundo a idade da gestação em que foram realizados os exames

\begin{tabular}{cc}
\hline Idade da gestação & Número \\
\hline 2 meses & 6 \\
3 meses & 22 \\
4 meses & 31 \\
5 meses & 13 \\
6 meses & 5 \\
7 meses & 18 \\
8 meses & 7 \\
9 meses & 1 \\
\hline Total & 103 \\
\hline
\end{tabular}

Graças a técnica apropriada de colheita de urina, a contaminação pode ser reduzida ao mínimo. Julgamos que a colheita da amostra ao jacto é suficiente. após cuidadosa antissepsia dos grandes lábios e região periuretral.

A partir do material, assim colhido, foram realizados imediatamente, os seguintes exames: tipo I. urocultura com quantificação de colônias e as provas de despistagem (provas do nitrito, da catalase. do trifenil-tetrazólio (T.T.C.), e a combinada T.T.C. + nitrito).
Nas uroculturas foi empregada a técnica de Holprich ${ }^{5}$ (1960) e nas provas de despitagem foram usados os métodos indicados por Bullen e Kincaid-Smith ${ }^{1}$ (1969).

\section{Lirocultura}

Após homogeinização, invertendo-se o frasco 23 a 25 vezes, eram semeados rolumes de 0.01 e $0.001 \mathrm{ml}$ de urina. em placas de agar sangue de coelho e de agar eosina-azul de metileno de Levine (Difco). Nas semeaduras, foram usadas duas alças de níquel-cromo, com diâmetros medindo, respectivamente, $4 \mathrm{~mm}$ e 1.45 mm. Em seguida, após a incubação das placas semeadas, a $37^{\circ} \mathrm{C}$ por 24 horas, procedia-se a contagem do número de colônias. com características morfológicas diferentes. A seguir, após o seu isolamento. algumas colonias eram submetidas a proras bioquímicas de identificação.

\section{Prova da Catalase}

Nesta prova. um disco de papel de filtro O.P. $6772\left(80 \mathrm{~g} / \mathrm{m}^{2}\right)$. medindo 12 $\mathrm{mm}$ de diâmetro, esterilizado. era mergulhado na urina e posteriormente colocado num tubo de ensaio $16 \times 160 \mathrm{~mm}$. também esterilizado. A seguir, neste tubo, eram adicionados $5 \mathrm{ml}$ de solução de água oxigenada a $3 \zeta^{\prime}$ e, anotava-se o tempo necessário para o papel de filtro voltar à superfície. A prova era considerada positiva quando este tempo não excedia de uma hora.

\section{Provas do Nitrito}

1. Prova direta - esta prova consistiu na mistura. em placa de porcelana branca escavada, de 6 gotas de urina com 2 gotas de cada um dos reagentes: solução A-12,5 g de ácido sulfanílico em $500 \mathrm{ml}$ de solução de ácido acético a $30 \%$; solução B-25,0 g de naftilamina em $500 \mathrm{ml}$ de solução de ácido acético a $30 \%$.

A prova era considerada positiva, quando surgia cor rósea a vermelho-escura, 
CIARI Jr., C. et al. - A importancia das provas de despistagem da bacteruúrı assintomátıca em servicos de pré-natal. Rer. Saúle puibl., S. Paulo, 9:25-31. 1975.

imediatamente após a adição dos reagentes.

2. Proza em tubo - na realização desta prova, em um tubo de ensaio esterilizado, procedia-se a mistura de $u m \mathrm{ml}$ de urina com $0.4 \mathrm{ml}$ de solução de nitrato de potássio a $5{ }^{c} c$. Após uma incubação a $37^{\circ} \mathrm{C}$ por 4 horas, adicionavam-se 0.5 $\mathrm{ml}$ de cada uma das soluçōes (A e B). referidas na prova direta. $O$ aparecimento de cor rósea a rermelho-escura, imediatamente após a adição dos reagentes. caracterizava a prova como positiva.

\section{Prova do Cloreto de Trifenil-Tetrazólio (T.T.C.)}

- Vesta prova. eram misturados, assepticamente, em um tubo de ensaio, um $\mathrm{ml}$ de urina e $0.25 \mathrm{ml}$ de solução de cloreto de trifenil-tetrazólio. A formação de um precipitado de cor rósea, após uma incubação a $37^{\circ} \mathrm{C}$ por 4 horas, caracterizava uma reação positiva.

As soluções de cloreto de trifenil-tetrazólio foram preparadas da seguinte forma: solução "estoque" - $750 \mathrm{mg}$ de T.T.C. em $100 \mathrm{ml}$ de solução saturada de fosfato dissódico ( $\left.\mathrm{Na}_{2} \mathrm{HPO}_{1}\right)$; solução usada na prova - $4 \mathrm{ml}$ de solução "estoque" em $100 \mathrm{ml}$ de solução saturada de fosfato dissódico. Ambas as soluçōes foram esterilizadas por filtração.

\section{Prova Combinada (T.T.C. + Nitrito)}

Na execução desta prova, eram misturados em um tubo de ensaio esterilizado. $0.25 \mathrm{ml}$ de solução de T.T.C. adicionada de $1 \%$ de nitrato de potássio e. um $\mathrm{ml}$ de urina. Após uma incubação de 4 horas a $37^{\circ} \mathrm{C}$, procedia-se a leitura da prova do T.T.C. (formação de precipitado róseo a vermelho) e a seguir a do nitrito, adicionando-se $0.5 \mathrm{ml}$ de cada uma das soluçôes $\mathrm{A}$ e $\mathrm{B}$, já descritas anteriormente. A prova do nitrito era considerada positiva quando surgia cor rósea a vermelho-escura. logo após a adição dos reagentes.
RESLLTADOS

Observamos após a realização de todos os exames que, no grupo de gestantes estudadas 1103 i. a frequêencia da bacteriúria assintomática foi de $5.83 \mathrm{C}^{\mathrm{c}}$. isto é, 6 gestantes. Esta incidência é concordante com todos os autores. Testas 6 gestantes, as contagens de colônias na urocultura, foram superiores a $300.000 / \mathrm{ml}$ de urina. Destas 5 foi isolada a Escherichia coli e em uma, a Proteus mirabilis.

Outras 10 pacientes apresentaram urocultura positiva para estafilococos. com contagens variando entre 7.600 e $70.000 /$ $\mathrm{ml}$ de urina e. portanto, sempre abaixo do valor crítico de $100.000 / \mathrm{ml}$.

As 6 gestantes com eridente bacteriúria assintomática, apresentaram (Tabela 2) sempre, a prova do nitrito em tubo e a do nitrito na prova combinada. positiva $1100 \%)$.

Além do mais esta prova, não deu positiva em nenhum outro caso, no qual não havia bacteriúria significatira assintomática.

Ao contrário, para as 6 gestantes com hacteriúria significativa assintomática, a prova da catalase foi positiva apenas em 2. Nas gestantes que não apresentavam bacteriúria assintomática (97). ela foi positiva em 10.

Isto revela portanto, que esta prova dá frequentemente reaçós falsas positivas ou falsas negativas.

A prova do nitrito em placa só foi positiva para a urina de uma gestante com hacteriúria assintomática. sendo portanto. pouco sensível e a prova do T.T.C. não foi positiva em nenhum caso.

\section{ISCLSSAO}

Na atualidade é difícil identificar as pacientes que possam, eventualmente, desenvolver processos renais agudos. Em conseqüência. muitos autores, creem que é aconselhável examinar de forma habitual a todas as pacientes. no prenatal, para detectar as bacteriúrias, pois, quando se 
CIARI Jr., C. et al. - A importância das provas de despistagem da bacteriúria assintomática em serviços de pré-natal. Rev. Saúde públ., S. Paulo. 9:25-31, 1975.

TA BELA 2

Resultados das provas de despistagem de bacteriúria assintomática em urinas de gestantes com uroculturas positivas e negativas

\begin{tabular}{|c|c|c|c|c|c|c|c|}
\hline \multirow{3}{*}{ Urocultura } & \multirow{3}{*}{$\begin{array}{c}\text { Número } \\
\text { de } \\
\text { ges- } \\
\text { tantes }\end{array}$} & \multirow{3}{*}{$\%$} & \multicolumn{5}{|c|}{$\begin{array}{c}\text { Provas de despistagem de bacteriúria } \\
\text { assintomática, positivas }\end{array}$} \\
\hline & & & \multirow{2}{*}{ Catalase } & \multicolumn{2}{|c|}{ Nitrito } & \multicolumn{2}{|c|}{ Combinada } \\
\hline & & & & Placa & Tubo & T.T.C. & Nitrito \\
\hline $\begin{array}{l}\text { Positiva-Bacteriúria } \\
\text { superior a } 100.000 / \mathrm{ml}\end{array}$ & 6 & 5.83 & 2 & 1 & 6 & - & 6 \\
\hline $\begin{array}{l}\text { Positiva-Bacteriúria } \\
\text { inferior a } 100.000 / \mathrm{ml}\end{array}$ & 10 & 9.70 & 2 & - & - & - & 一 \\
\hline Negativa & 87 & 84,47 & 8 & - & - & - & - \\
\hline Total & 103 & 100.00 & 12 & 1 & 6 & - & 6 \\
\hline
\end{tabular}

obtém resultados positivos deve-se tentar erradicar a infecção. Como sabemos a incidência da bacteriúria assintomática na gestação é de 2 a $7 \%$ (Hellman e Pritchard $^{3}, 1971$ ) e para alguns de 6 a $7 \%$ (Bullen e Kincaid-Smith ${ }^{1}$, 1969).

Gruneberg e col. 2 (1969). Nordem \& Kilpatrick ${ }^{13}$ (1965), Little ${ }^{12}$ (1966), Savage $^{16}$ (1967) e Whalley ${ }^{18}$ (1967), assinalam que em média $25 \%$ de mulheres com bacteriúria assintomática, desenvolvem no evolver da gestação, uma infecção urinária aguda sintomática. Estes mesmos autores demonstram que a eliminaçāo da bacteriúria assintomática por meio de agentes antimicrobianos, resulta efetiva para prevenir estas infecçôes.

Com relação ao parto prematuro e ao aumento de morbidade e mortalidade neonatal. os autores são discordantes. Assim. Kass $^{\top}$ (1965) revela que a incidência de partos prematuros é muito mais elevada nas gestantes com bacteriúrias não tratadas, do que nas submetidas a tratamento. Por sua vez, Kincaid-Smith e Bullen's (1965) informam também que há uma proporção relativamente alta de recém-nascidos com peso baixo ao nascer, entre mulheres com bacteriúrias assintomáticas não tratadas, porém eles não conseguiram diminuir de maneira significativa esta proporção mediante tratamento antimicrobiano.

Todos estes aspectos nos fazem afirmar que um controle pré-natal moderno deve revelar a existência de uma bacteriúria assintomática, para podermos tratá-la convenientemente.

Não temos dúvida que o método ideal para o diagnóstico correto de uma bacteriúria assintomática. é o da urocultura. Porém, este método é impraticável em serviços de pré-natal sobrecarregados de gestantes, por ser dispendioso e além do mais, demorado. As provas de despistagem, por nós utilizadas, revelaram-se eficazes na triagem das gestantes com bacteriúrias assintomáticas, pois a prova do nitrito em tubo manifestou-se positiva em $100 \%$ dos casos com bacteriúria assintomática significativa, identificada pela urocultura. Bullen e Kincaid-Smith ${ }^{1}$ 
CIARI Jr., C. et al. - A importância das provas de despistagem da bacteriúria assintomátlca em serviços de pré-natal. Rev. Saúde puibl., S. Paulo, 9:25-31, 1975.

(1969) também observaram resultados semelhantes, revelando a importância desta prova de despistagem de bacteriúria assintomática. Esta prova baseia-se na propriedade que têm certos microorganismos de reduzir os nitratos a nitritos. Isto é importante, pois, nas infecçōes urinárias por Escherichia coli ou Proteus sp., responsáveis pela grande maioria das bacteriúrias na gestaçáo, a prova do nitrito em tubo é positiva.

A prova combinada utilizando o T.T.C. e o nitrito, teria a função principal de detectar também as bacteriúrias por estreptococo e estafilococo, que não o são pela prova de nitrito em tubo. No nosso trabalho, tal fato não pode ser evidenciado, pois, das 6 gestantes com bacteriúria assintomática, de 5 isolaram-se cepas de Escherichia coli e de uma, cepa de Proteus mirabilis. Nos casos em que a urocultura foi positiva para estafilococo, porém, com bacteriúria abaixo de $100.000 / \mathrm{ml}$ a prova do T.T.C. foi sempre negativa.

A prova da catalase, por sua vez, evidenciou apenas 2 dos 6 casos de bacteriúria assintomática detectados, revelando-se pouco sensível. Ao contrário, em 10 gestantes que não apresentavam bacteriúria significativa esta prova forneceu resultados falsos positivos. Este aspecto nos é efetivamente revelado por Bullen e Kincaid-Smith $^{1}$ (1969).

Vemos assim que, destas provas de despistagem utilizadas, deveremos dar valor e estudar, mais detalhadamente, a prova do nitrito em tubo ou então a associação desta com a do T.T.C. que nos permitiria evidenciar possíveis casos de infecçōes por microorganismos não redutores do nitrato.

A prova do nitrito em tubo é simples e rápida na sua realização, podendo ser feita em apenas 4 horas. Pode, portanto, ser empregada de rotina em serviços de prénatal e para crianças em idade escolar, na triagem de bacteriúrias assintomáticas, as quais, devem ser posteriormente, confirmadas através da urocultura.

\section{CONCLUSOES}

1) Das provas estudadas, a do nitrito em tubo é a que efetivamente forneceu resultados satisfatórios, comparáveis aos da urocultura, sendo que os resultados de sua associação com a do T.T.C. devem ser melhor estudados no sentido de verificar seu valor na detecção de bactérias não redutoras do nitrato.

2) Pela simplicidade, facilidade e rapidez de execução, das provas de despistagem, bem como da possibilidade de aplicação em grandes grupos, estas provas podem ser realizadas de rotina em serviços de pré-natal para a detecção de bacteriúria assintomática, aspecto este muito importante na atenção da gestante.

RSPU-B/244

CIARI Jr., C. et al. - [The importance of screening for assymptomatical bacteriuria in pre-natal services.] Rev. Saúde públ., S. Paulo, 9:25-31, 1975.

SUMMARY: Screening for assymptomatical bacteriuria in 103 pregnant women grouped according to the age of pregnancy was performed. The results were compared with those obtained by urocultures. The nitrite tube test proved to be important in the screening for assymptomatical bacteriuria throughout pregnancy.

UNITERMS: Prenatal care. Assymptomatical bacteriuria. Screening test. 
CIARI Jr, C. et al. - A importância das provas de despistagem da bacteriúria assintomática em servicos de pré-natal. Rev. Saúde públ., S. Paulo, 9:25-31, 1975.

\section{REFERENCIAS BIBLIOGRAFICAS}

1. BULLEN, M. \& KINCAID-SMITH, P. Provas de despistagem das infecçōes urinárias. Triângulo, 8:49, 1969.

2. GRUNEBERG, R.N. et al. - Re'ationship of bacteriúria in pregnancy to acute pyelonephritis, prematurity and fetal malformations. Lancet, 2:1-3, 1969.

3. HELLMAN, L.M. \& PRITCHARD, J,A. - Williams, Obstetrics. 15th. New York, Appleton-Century-Croft, 1971.

4. HENDERSON. M. \& REINTE, W.A. The relationship between bacteriúria and prematurity. In: KASS, E.H. Progress in pyelonephritis. Philadelphia, Davis Co., 1965. p. 27.

5. HOEPRICH, P.D. - Culture of the urine. J. Lab. clin. Med., 56:899-907, 1960 .

6. HUTCH, J.A.: AYRES, R.D. \& NOLI, L.E. - Vesicoureteral reflux as cause of pyelonephritis of pregnancy. Amer. J. Obstet. Gynec., 87:478-85, 1963 .

7. KASS, E.H. - Progress in pyelonephritis. Philadelphia, Davis Co., 1965.

8. KINCAID-SMITH, P. \& BULLEN, M. Bacteriúria in pregnancy. Lancet, $1: 395-9, \quad 1965$

9. KUNIN, C.M. et al. - Urinary tract infection in school children: an epidemiology, clinical and laboratory study. Medicine, 43:91-130, 1964.

10. LAYTON, R. - Infection of the urinary tract in pregnancy: an investigation of a new routine in antenatal care. $J$. Obstet. Gynec. Brit. Cwth., 71: 927-33, 1964 .

11. LITTLE, P.J. - Prevention of pyelonephritis of presnancy. Lancet, 1:5679,1965 .

12. IITTLE, P.J. - The incidence of urinary infection in 5.000 pregnant women. Lancet, 2:925-8, 1966.

13. NORDEN, C.W. \& KILPATRICK, W.H. - In: KASS, E.H. - Progress in pyelonephritis. Davis Co., Philadelphia, 1965. p. 64.

14. RANNEVICK, G. - Asyntomatusk bakteriuri obstetriska synpunkten. Symposium, Med. Riksstamman, Stockholm, 1965. A.B. Tika, Umea, 1966.

15. SALA, N.L. \& RUBI, R.A. - Ureteral function in pregnant women. Amer. J. Obstet, Gynec., 99:228-36, 1967.

16. SAVAGE, W.E. et al. - Demographic and prognostic characteristics of bacteriuria in pregnancy. Medicine, $\mathbf{4 6}$ : 385-407, 1967.

17. STUART, L.L. et al. - Bacteriuria, prematurity, and the hypertensive disorders of pregnancy. Brit. Med. J., $1: 554-6,1965$

18. WHALLEY, P.J. - Bacteriuria of pregnancy. Amer, J. Obstet. Gynec., 97: 723-38, 1967.

Recebido para publicaça em 13-12-74 A provado para publicasão em 13-01-75 